\title{
Distributions of Potential and Contact-Induced Charges in Conventional Organic Photovoltaics
}

\author{
Kouki Akaike \\ National Institute of Advanced Industrial Science and Technology, Tsukuba 305-8565, Japan; \\ kouki.akaike@aist.go.jp; Tel.: +81-029-849-1221
}

Received: 25 March 2020; Accepted: 22 May 2020; Published: 24 May 2020

check for updates

\begin{abstract}
The interfaces of dissimilar materials play central roles in photophysical events in organic photovoltaics (OPVs). Depth profiles of electrostatic potential and contact-induced charges determine the energy-level lineup of the frontier orbitals at electrode/organic and organic heterointerfaces. They are critical for the elementary processes in an OPV cell, such as generation and diffusion of free carriers. A simple electrostatic model describes the energetics in organic heterojunctions supported by an electrode, and experiments via photoelectron spectroscopy and the Kelvin probe method validate the potential distribution in the stacking direction of the device. A comparative study has clarified the significance of Fermi-level pinning and resulting electrostatic fields in determining the energy-level alignment. In this review, we discuss how parameters of device constituents affect the distributions of potential and the dark charges in conventional OPVs comprising metallophthalocyanine and $\mathrm{C}_{60}$ as donor and acceptor, respectively. The results of previous studies, together with additional numerical simulations, suggest that a number of the factors influence the depth profiles of the dark charge and potential, such as the work function of bottom materials, layer thickness, structural inhomogeneity at interfaces, top electrode, and stacking sequence.
\end{abstract}

Keywords: donor/acceptor interface; electrode interface; energy-level alignment; dark charges; organic solar cells

\section{Introduction}

Organic photovoltaics (OPVs) have attractive potentials that ubiquitously harness solar energy. Benefits of OPVs, such as being lightweight, their flexibility, color tunability, and the low-cost production, have enabled steady progress in utilizing the devices for wearable electronics [1], self-powered buildings, and solar-powered automobiles with an option of the use of semitransparent solar cells for windows and skylights [2,3]. The development of new dyes and interface materials, and the controlling morphology of photoactive layers have contributed to improvements in photoelectric conversion and device stability [4]. Use of non-fullerene acceptors, in particular, boosts power conversion efficiency to over $17 \%$ [5] and even 18\% for a single-junction OPV cell [6]. The performance of OPVs in state-of-the-art applications relies on the optoelectronic properties of their constituents $[3,4,7,8]$. Large absorption coefficients in the visible-light range and sufficient charge mobility are prerequisites for donor and acceptor. Formation of Frenkel excitons and transport of photogenerated charges are determined by these parameters. Key electronic processes in OPVs, such as free-charge generation/recombination and extraction, on the other hand, occur at the interfaces of molecular semiconductors and electrodes. Energy levels play decisive roles in the elementary events: energy offsets of the frontier orbitals at the donor/acceptor interface are required to form charge-transfer (CT) states that are precursors of free charges. As for charge extraction, built-in potential at electrode/organic interfaces can assist free charges swept toward anode and cathode $[9,10]$. Considering these aspects, experimental demonstration and mechanistic modeling of energy-level alignment are essential for the rational design based on respective 
device constituents. Photoelectron spectroscopy and the Kelvin probe method (KP) have been used to directly measure the energy-level shifts at the interface of organic semiconductors [11-17]. A number of ultrahigh vacuum (UHV)-based studies via ultraviolet photoelectron spectroscopy (UPS) and KP have revealed energy shifts over the nominal thickness of several tens of nanometers from electrode/organic and organic heterointerfaces. Origins of the energy shift were typically interpreted as a consequence of the ground-state charge transfer at the interfaces. The formation of interface dipole may account for the observed energy shift [12,18]. However, the magnitude of the shift near the interfaces largely depends on the position of the Fermi level $\left(E_{\mathrm{F}}\right)$ of a bottom layer $[15,19,20]$. Moreover, non-monotonic energy shifts have been reported for donor/acceptor interfaces [13,16,21]. These observations were not explained by solely assuming the formation of the dipole layer. An electrostatic model reported by Oehzelt et al. [22] comprehensively substantiated these observations by quantifying profiles of the contact-induced charge density that is also given in these model simulations.

Complementary studies employing photoemission spectroscopy and these simulations based on the model have clarified the decisive roles of the Fermi-level pinning and induced electrostatic fields in determining energetic landscape at organic semiconductor interfaces $[21,23,24]$. Based on these findings, we will discuss how parameters of the device, such as layer thickness, etc., influence the behavior of Fermi-level pinning and then potential/contact-induced charge distributions at the electrode/organic and organic donor/acceptor interfaces. Analysis of the charge density profile along the stacking direction explains the modification of potential distributions through presence of structural disorder and top electrodes. The electrostatic simulations detail the mechanism of the changes in the distributions upon the contact of heteromolecules. We chose metallophthalocyanine and $\mathrm{C}_{60}$ as a prototypical donor and acceptor used in conventional OPVs, respectively. One of benefits of the use of these molecules in basic research is that the electronic structure of the materials is already known [25-28]. Moreover, comprehensive understanding on the distributions of potential and charge density in conventional OPVs will be helpful to differentiate between recent molecules that enable barrierless charge density separation [29] from prototypical organic semiconductors.

\section{Charged Molecules at Electrode/Organic Interfaces in the Ground State}

Organic semiconductors are often used without intentional doping. The intrinsic charge density $\left(n_{\mathrm{i}}\right)$ of an organic film was calculated from the energy gap, spin degeneracy, and dispersion of Gaussian functions, modeling the highest occupied molecular orbital (HOMO) and lowest unoccupied molecular orbital (LUMO) of a molecule [30]. Assuming Boltzmann distribution and equal density for thermally excited holes and electrons, $n_{\mathrm{i}}$ for metal-free phthalocyanine $\left(\mathrm{H}_{2} \mathrm{Pc}\right)$ was estimated to be $1.0 \times 10^{8} \mathrm{~cm}^{-3}$. Such a low value was actually demonstrated for a $\mathrm{H}_{2} \mathrm{Pc}$ crystal $\left(8.86 \times 10^{6} \mathrm{~cm}^{-3}\right)$ [31]. The low value of $n_{\mathrm{i}}$ is simply due to the large energy gap of the molecule. In practical devices such as an OPV cell, a molecular semiconducting film is sandwiched between bottom and top electrodes. The surfaces of the two electrodes are in general modified with organic or inorganic material that tune the work function in the range of 2.5-7 eV and make electrode contacts ohmic. Analysis of photoelectron spectra demonstrated the presence of charged species right at the electrode interface [32-36]. Molecular cations are present at the interface with high-work function substrates, such as $\mathrm{MoO}_{3}$-covered metal $[35,36]$, while anions appear at the electron-injection/extraction interface [32].

A numerical model that assumes the Fermi-Dirac occupation [22] rationalized the formation of the charged species near the electrode interfaces. In brief, the model simulates depth-resolved distributions of electrostatic potential and charge density in ground states. The model assumes that the bottom electrode is an electron reservoir with a constant chemical potential, namely, $E_{\mathrm{F}}$; electron occupation obeys the Fermi-Dirac statistics under thermodynamic equilibrium through the heterostructure. Therefore, electron exchange can freely occur between the organic layer and the 
bottom electrode. The resulting charges in the organic layers, ideally formed in the Frank-van der Merwe mode, are calculated using:

$$
\rho(z)=e \cdot n \cdot\left\{\int_{-\infty}^{\infty} f_{\mathrm{h}}(E) \cdot D_{\mathrm{H}}[E+e V(z)] d E-\int_{-\infty}^{\infty} f_{\mathrm{e}}(E) \cdot D_{\mathrm{L}}[E+e V(z)] d E\right\}
$$

where $e$ is the elementary charge, $n$ is the molecular number density per area layer, and $f_{\mathrm{h}}$ and $f_{\mathrm{e}}$ are the Fermi-Dirac functions for holes and electrons, respectively. $D_{\mathrm{H}}$ and $D_{\mathrm{L}}$ are the density of states (DOS) shapes for the HOMO and LUMO, respectively. $V(z)$ is the potential at the distance $\mathrm{z}$ from the substrate surface. The one-dimensional Poisson equation gives the potential of respective organic layers.

$$
\nabla(\varepsilon(z) \nabla V(z))=-\frac{\rho(z)}{\varepsilon_{0}}
$$

where $\varepsilon_{\mathrm{r}}(z)$ is the dielectric constant at the distance $z$ and $\varepsilon_{0}$ is the permittivity in a vacuum. The obtained potential is used to again calculate charges by solving Equation (1), and then a new $V(z)$ is calculated from Equation (2). This self-consistent calculation can simulate depth-resolved charge density and potential distributions. Numerical simulations were able to reproduce well the observed energy shifts by photoemission spectroscopy for electrode/organic [32] and organic heterointerfaces [21,23,24]. All calculations were carried out using Mathematica software (12.0.0.0, Wolfram Research, Champaign, IL, USA).

Figure 1a illustrates the calculated distribution of contact-induced charge density in a zinc phthalocyanine $(\mathrm{ZnPc})$ film with thickness of thirty layers. ZnPc molecules presumably adopt edge-on orientation in the film, which has actually been demonstrated [37-39]. It is obvious that holes accumulate right at the substrate interface, and that their amount depends on substrate work function $\left(W_{\text {sub }}\right)$. When a substrate with higher $W_{\text {sub }}$ is employed, more holes are generated. Hole concentration is negligible for a $W_{\text {sub }}$ value of below $5 \mathrm{eV}$. These findings are explained as follows. If the $E_{\mathrm{F}}$ of a bottom electrode is located deeper than the HOMO of a $\mathrm{ZnPc}$ film, electrons in the $\mathrm{ZnPc} H O M O$ are emptied and transferred to the electrode. Since the ionization energy of an edge-on $\mathrm{ZnPc}$ molecule in solid state is $4.8 \mathrm{eV}$ [40], the substrate with a $W_{\text {sub }}$ higher than this value removes electrons from the contacting molecules.

The hole accumulation leads to a downward potential shift near the electrode interface. Figure $1 \mathrm{~b}$ shows the evolution of work function in the $\mathrm{ZnPc}$ film. Work function gradually decreases as a function of thickness for $W_{\text {sub }}$ of $\geq 5 \mathrm{eV}$, because of the positive charges in the film. The final work function of the $\mathrm{ZnPc}$ layer reaches a common value, $4.5 \mathrm{eV}$. This behavior is known as Fermi-level pinning [41]. The same phenomenon is also referred to as quasi-Fermi level pinning [42]. No significant change of work function, on the other hand, is present when $W_{\text {sub }}$ is well below the ionization energy of an edge-on $\mathrm{ZnPc}$ molecule. The vacuum level aligns throughout the film in this case.

Similar simulations were also carried out for $\mathrm{C}_{60}$. Figure $1 \mathrm{c}$ illustrates the evolution of charge density in a $\mathrm{C}_{60}$ film of thirty layers as a function of thickness. Negative charges are generated at the interface of electrodes with a $W_{\text {sub }}$ of up to $4 \mathrm{eV}$, whereas no significant amounts of charged molecules appear when the $C_{60}$ film is formed on the substrate with a $W_{\text {sub }}$ of over $4 \mathrm{eV}$. The lower work function a substrate has, the more electrons are accumulated at the electrode interface. Since the LUMO of the $\mathrm{C}_{60}$ molecule is $3.98 \mathrm{eV}$ [43], the electrode with a $W_{\text {sub }}$ lower than this value occupies electrons in the unoccupied states of $\mathrm{C}_{60}$.

The electron occupation in a $\mathrm{C}_{60}$ film alters potential distribution. Figure $1 \mathrm{~d}$ illustrates the

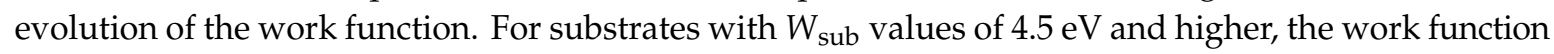
is constant in a whole range of thicknesses, that is, vacuum level aligns throughout the $C_{60}$ film. On the

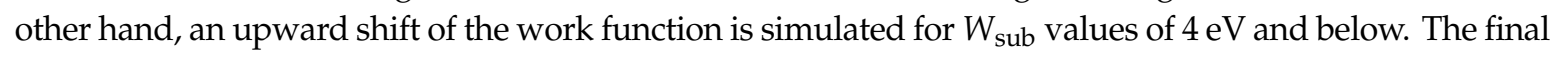
work function of the $\mathrm{C}_{60}$ film reaches a common value. Here, the Fermi-level pinning occurs at the interface with low work-function electrodes. The pinning behaviors simulated for metallophthalocyanine 
and $\mathrm{C}_{60}$ films were actually demonstrated by Kelvin probe measurements (Figure 2) [44]. The arrows indicated in Figure 2 show the onset points where the Fermi-level pinning begins.

(a)

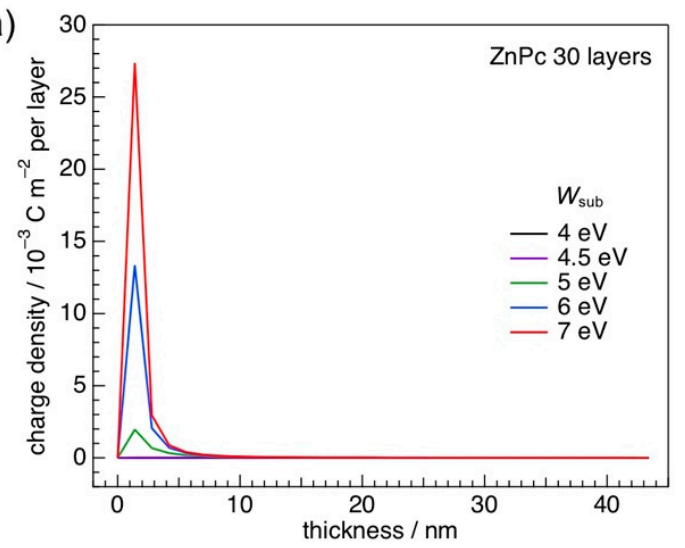

(c)

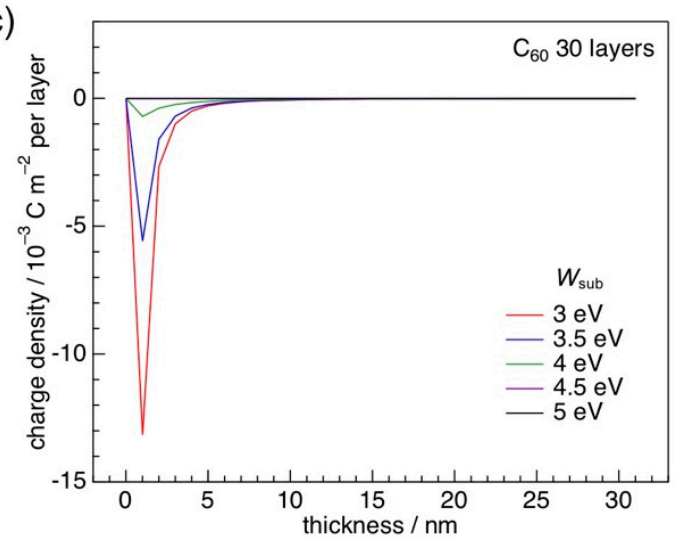

(b)

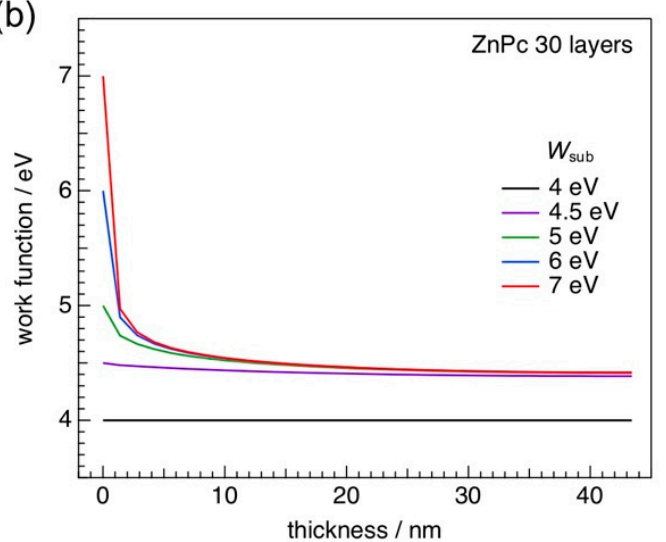

(d)

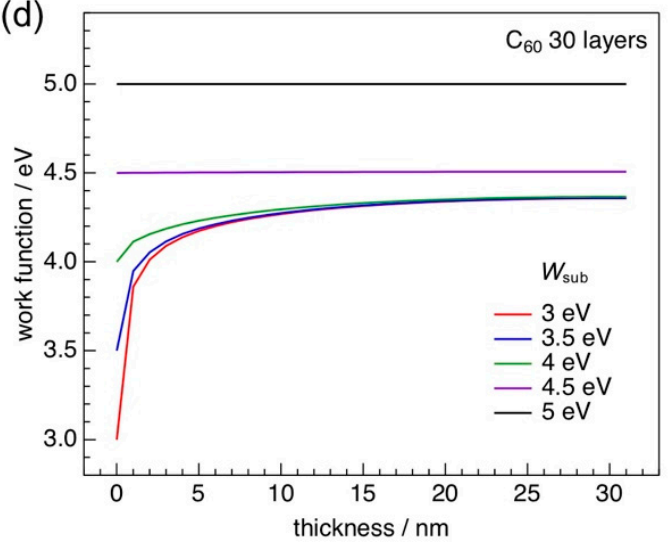

Figure 1. (a) Evolution of charge-density distributions in a ZnPc layer on a substrate with work functions of 4-6 eV as a function of film thickness. (b) Corresponding potential distributions are shown. $\mathrm{ZnPc}$ molecules are assumed to adopt edge-on orientation that is typically observed for films prepared on practical electrodes for organic photovoltaics (OPVs). (c) Evolution of the work function in a $\mathrm{C}_{60}$ layer on a substrate with work functions of $3-5 \mathrm{eV}$ as a function of film thickness. (d) Corresponding charge-density distributions are plotted. Simulation parameters for both $\mathrm{ZnPc}$ and $\mathrm{C}_{60}$ can be found in the supporting information of Ref. [23].

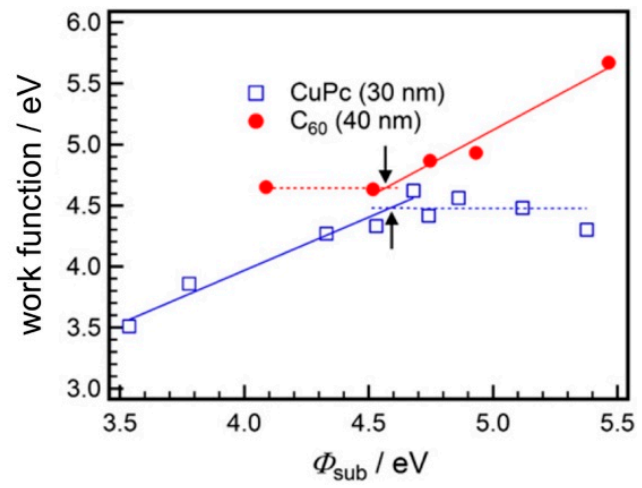

Figure 2. Evolutions of work functions for copper phthalocyanine ( $\mathrm{CuPc}$ ) and $\mathrm{C}_{60}$ films. Reprinted with permission [44].

Recent studies suggest that photocarriers recombine with dark charges near the electrodes, which reduces the fill factor in highly efficient OPVs $[45,46]$. The occurrence of Fermi-level pinning at the 
electrode interfaces has been thought to be a must for ohmic contact, but that design is too simple for designing OPV. $W_{\text {sub }}$ has to be optimized to trade off ohmic contact and the recombination of photocarriers via dark charges.

\section{Distributions of Potential and Charge Density in Organic Heterojunctions}

\subsection{Fermi-level Pinning at Organic Heterointerfaces}

We next address energy-level alignment at organic heterointerfaces. One of known phenomena of energetics in organic heterojunctions is that the lineup of the frontier orbitals depends on the $E_{\mathrm{F}}$ of the bottom layer $[15,19,20]$. Figure 3a shows an example of a substrate-dependent energy-level alignment. The change in the work function of the $\mathrm{C}_{60}$ layer, on top of the $\mathrm{CuPc}$ film, became larger when the bottom layer was formed on a substrate with an original work function of $<4 \mathrm{eV}$ [44]. The work function of the $\mathrm{CuPc}$ layer on this substrate reached $3.8 \mathrm{eV}$, whereas the $\mathrm{CuPc}$ film on a UV-ozone treated indium tin oxide (ITO) had a work function of $\sim 4.5 \mathrm{eV}$. Since the former value is less than the electron affinity of $\mathrm{C}_{60}$, electrons occupy the LUMO of $\mathrm{C}_{60}$ upon interface formation, according to the Fermi-Dirac statistic. As a result, an upward shift of $0.8 \mathrm{eV}$ was induced in the $\mathrm{C}_{60}$ layer. Note that the final work function of the $\mathrm{C}_{60}$ layer reached $\sim 4.5 \mathrm{eV}$. This value is in good agreement with the onset where the $E_{\mathrm{F}}$-pinning to the LUMO starts (see Figure 2). The experimental result demonstrated that Fermi-level pinning occurs at organic heterointerfaces.
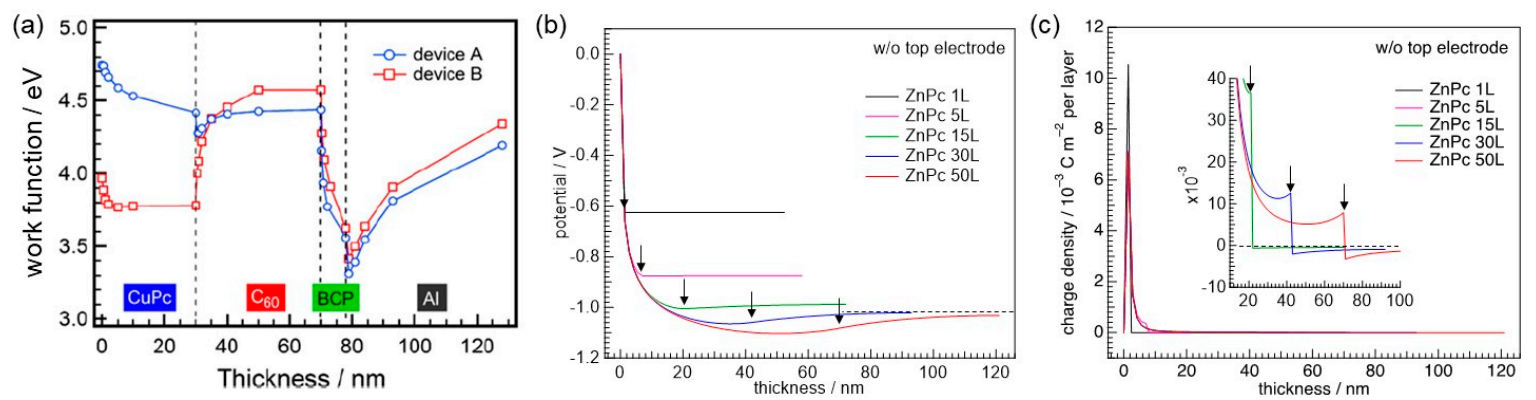

Figure 3. (a) Evolutions of measured work functions against thicknesses of components in planar-heterojunction $\mathrm{CuPc} / \mathrm{C}_{60}$ OPVs. Device A was constructed on a UV-ozone treated ITO substrate, whereas device B was constructed on an ITO covered with an Al film of $1 \mathrm{~nm}$. The latter substrate has a lower work function than a UV-ozone treated ITO, causing a significant change in the evolution of the vacuum level in the $\mathrm{C}_{60}$ layer. Reprinted with permission [44]. (b) Potential distributions in $\mathrm{ZnPc}_{6} \mathrm{C}_{60}$ heterojunctions with various thicknesses of $\mathrm{ZnPc}$. The work function of the bottom substrate is assumed to be $5.5 \mathrm{eV}$. $\mathrm{C}_{60}$ thickness was fixed to be fifty layers. The dashed line indicates a saturated value of work function for the $\mathrm{C}_{60}$ top layer. (c) Depth-resolved charge density profile for the heterojunction with various thicknesses of $\mathrm{ZnPc}$ layers. The arrows in (b) and (c) indicate the positions of each heterointerface. The results shown in (b) and (c) ignore the impact of top electrodes on the distributions.

Pinning behavior was also simulated for $\mathrm{ZnPc} / \mathrm{C}_{60}$ interfaces with various thicknesses of the bottom phthalocyanine layer (Figure $3 \mathrm{~b}$ ). To calculate the distributions of potential and charge density, $W_{\text {sub }}$ was set to be $5.5 \mathrm{eV}$. A common feature in Figure $3 \mathrm{~b}$ is the downward shift in the ZnPc bottom layer. Since $W_{\text {sub }}$ exceeds the ionization energy of $\mathrm{ZnPc}$, the positive charges are generated by emptying electrons from the $\mathrm{ZnPc} \mathrm{HOMO}$ (Figure 3c). Potential distribution near the heterointerface, however, varies with $\mathrm{ZnPc}$ thickness. Upward potential shifts are seen across the $\mathrm{ZnPc} / \mathrm{C}_{60}$ interface for the thickness of fifteen layers and above, whereas no significant shift is present for thinner ZnPc layers. The potential is saturated for the heterointerfaces with $\mathrm{ZnPc}$ thicknesses of thirty layers and above, as shown by the horizontal dashed line in Figure $3 \mathrm{~b}$. That is, the work function of the outermost $\mathrm{C}_{60}$ layer reaches a common value, which is again attributed to Fermi-level pinning at the heterointerface. 
The simulations revealed that work function of the $\mathrm{ZnPc}$ film reduced with increasing $\mathrm{ZnPc}$ thickness up to fifty layers from the monolayer, which was indeed demonstrated by KP measurements [47]. The charge density profiles at the heterointerface vary with ZnPc thickness, as shown in Figure 3c. In particular, the electron density in the $\mathrm{C}_{60}$ side increases when $\mathrm{ZnPc}$ thickness increases. The electron accumulation originates from the Fermi-level pinning of the $\mathrm{C}_{60}$ LUMO for the thicker ZnPc layer. As a result, the potential profile, opposite in sign to the depletion layer in the $p-n$ junction, is realized as seen in Figure 4a.
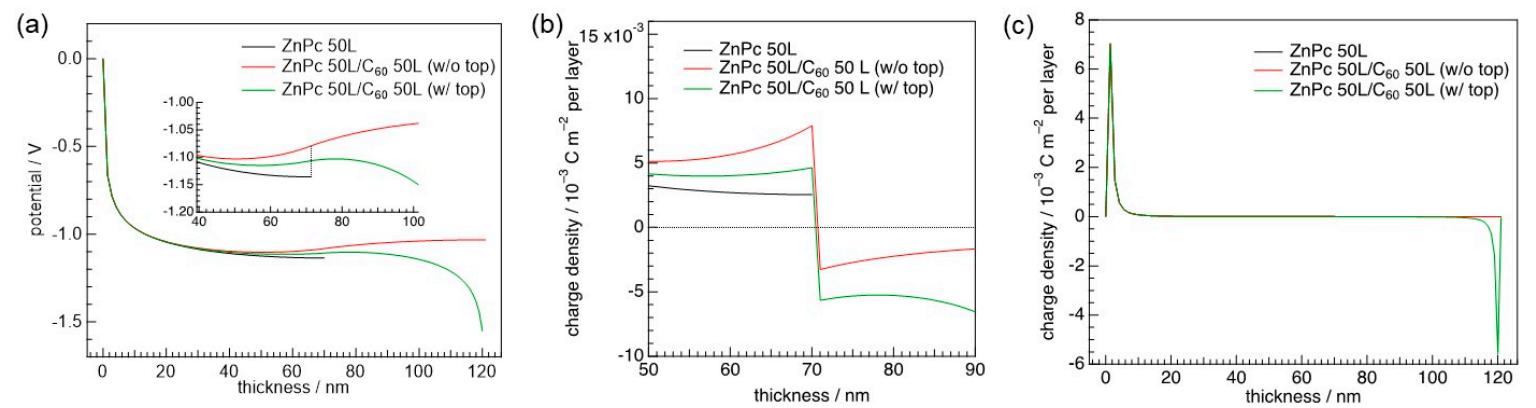

Figure 4. (a) Potential distributions of a $\mathrm{ZnPc}$ neat film (black) and $\mathrm{ZnPc} / \mathrm{C}_{60}$ heterojunctions with (green) and without a top electrode (red, work function $=3.5 \mathrm{eV}$ ). $W_{\text {sub }}$ was fixed to be $5.5 \mathrm{eV}$. $(\mathbf{b})$ Charge density profiles near the heterointerface are illustrated. The position of the heterointerface is located at a thickness of $70 \mathrm{~nm}$. The horizontal dashed line indicates a charge density of zero. (c) Charge density distributions in a whole range of thicknesses are illustrated.

Note that the rise of potential in the $\mathrm{C}_{60}$ layer moves the energy levels of the bottom $\mathrm{ZnPc}$ layer toward $E_{\mathrm{F}}$. This effect further emptied the $\mathrm{HOMO}$ of $\mathrm{ZnPc}$ right at the heterointerface. As a result, the hole density in the $\mathrm{ZnPc}$ side of the heterointerface increases after contact with $\mathrm{C}_{60}$ (Figure $4 \mathrm{~b}$ ).

\subsection{Consideration of Top Electrodes}

Distributions of potential and charge density are modified by taking a top electrode into account in the numerical calculations. The green curve in Figure 4a shows the potential shift in an anode $\left(W_{\text {sub }}=5.5 \mathrm{eV}\right) / \mathrm{ZnPc} / \mathrm{C}_{60} /$ cathode (work function $\left.=3.5 \mathrm{eV}\right)$ structure. It can be seen that the rise of potential across the $\mathrm{ZnPc} / \mathrm{C}_{60}$ interface decreases as compared to the heterojunction without the top electrode (red curve in Figure 4a). The change in the charge density profile near the heterointerface alters potential distribution (Figure $4 \mathrm{~b}$ ). Placing the electrode on top of the heterojunction decreases (increases) hole (electron) density in comparison to a case without the low-work-function electrode on top. Since thermodynamic equilibrium is achieved throughout the heterojunction, electrons flow from the top to bottom electrodes. The resulting potential gradient lowers the energy levels of both $\mathrm{ZnPc}$ and $\mathrm{C}_{60}$. This de-pins the HOMO of $\mathrm{ZnPc}$ to $E_{\mathrm{F}}$, whereas the $E_{\mathrm{F}}$ pinning of the $\mathrm{C}_{60}$ LUMO becomes more enhanced. This shift in the energy levels leads to the abovementioned change in charge density profile at the heterointerface with the contact of the top electrode.

\subsection{Structural Disorder at Donor/Acceptor Interface}

The electrostatic model used for the simulations assumes layer-by-layer growth of organic films and the formation of a sharp interface. However, realistic organic heterointerfaces involve molecular reorientation [40], chemical interaction [48], and the formation of an amorphous mixed phase [49]. As for phthalocyanine/ $C_{60}$ interfaces, the structural disordering upon the formation of the interface was speculated based on the analysis of the valence electronic structure. Figure $5 \mathrm{a}, \mathrm{b}$ show the UPS spectra for the $\mathrm{ZnPc}(10 \mathrm{~nm}) / \mathrm{C}_{60}$ interface prepared on $\mathrm{MoO}_{3}$-covered $\mathrm{Au}(111)$ in the secondary cutoff (SECO) and valence regions, respectively. The simulation for this heterojunction predicted vacuum-level alignment at the heterointerface [21]. The SECO spectra, however, demonstrated downward and then upward shifts of the vacuum level (Figure 5a). Concurrently, the peak of the ZnPc HOMO shifts 
toward higher binding energy, whereas the $\mathrm{C}_{60}$ HOMO peak shifts toward lower binding energy. This result clearly suggests that the formation of interface dipoles does not rationalize the opposite shift of the $\mathrm{ZnPc} \mathrm{HOMO}$ to $\mathrm{C}_{60} \mathrm{HOMO}$. As shown in Figure 5c, we noted that the HOMO of $\mathrm{ZnPc}$ became broader upon the deposition of $\mathrm{C}_{60}$ [21]. This broadening can indicate an increase in structural inhomogeneity, because the energy distributions of the HOMO and LUMO rely on the distribution of polarization energy in the system. Actually, a time-of-flight secondary ion mass spectroscopy (TOF-SIMS) study suggested intermixing at the edge-on $\mathrm{CuPc} / \mathrm{C}_{60}$ interface [50], which probably leads to an increase in the exponential DOS in the energy gap [51]. Considering the increased tailing of the $\mathrm{HOMO}$ of $\mathrm{ZnPc}$ right at the interface, we simulated the potential distribution at the $\mathrm{ZnPc} / \mathrm{C}_{60}$ interface (Figure 5d). This observation was reproduced by the simulations. The mechanism of energy-level alignment involving the increase in structural inhomogeneity was understood as follows. Tailing states of $\mathrm{ZnPc}$ reach the Fermi level upon the contact with $\mathrm{C}_{60}$. Fermi-Dirac statistics require the emptying of the electrons from the small occupied DOS within an energy gap. As a result, positive potential is generated, shifting the energy levels downward. Concurrently, ZnPc work function decreases. $E_{\mathrm{F}}$ is then pinned to the $\mathrm{C}_{60}$ LUMO, which leads to an upward shift in the thicker $\mathrm{C}_{60}$. The findings in this study suggest that an understanding of molecular arrangement at the heterointerface is essential. In particular, occurrence of intermixing and structural disordering for arbitrary heterointerfaces should thus be investigated thoroughly. STM studies have been reported for molecular bilayers to address this issue [52-54], but investigating the heterojunction with thicknesses relevant to realistic devices will be necessary.
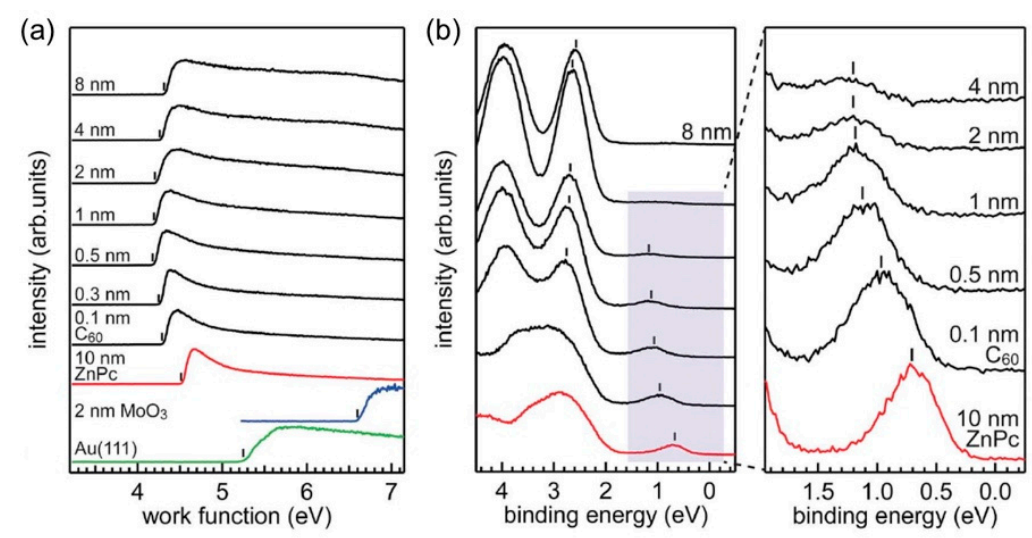

(c)

(d)
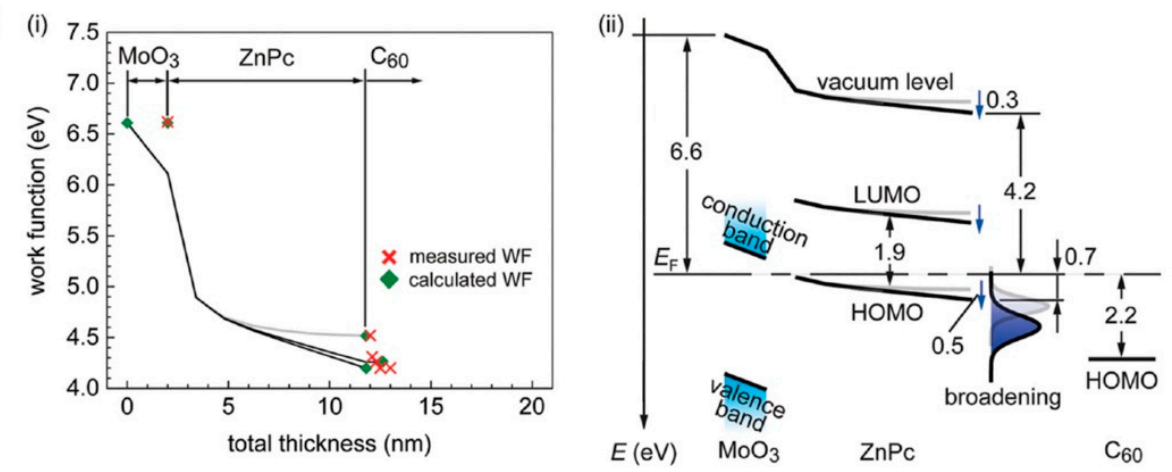

Figure 5. Evolutions of UPS spectra for the $\mathrm{ZnPc} / \mathrm{C}_{60}$ interface in (a) $\mathrm{SECO}$ and (b) valence regions shown as a function of $\mathrm{C}_{60}$ thickness. The right panel in (b) expands the valence spectra near the Fermi level. (c) Comparison of the HOMO peak for $\mathrm{ZnPc}$ before and after deposition of $0.1 \mathrm{~nm}$-thick $\mathrm{C}_{60}$. (d) (i) The shift of the work function. Black lines indicate electrostatic potentials. The measured and simulated work functions are denoted by red crosses and green diamonds, respectively. (ii) The energy diagram for the heterostructure is illustrated. The broadening of the $\mathrm{ZnPc} \mathrm{HOMO}$ produces positive charges and then a downward energy shift is induced. Reprinted with permission [21]. 


\subsection{Energy-Level Alignment in Reversed Stacking}

In a planar-heterojunction OPV cell, donor molecules make contact solely with an anode and acceptor molecules make contact with a cathode. Molecular composition near the electrodes in a bulk heterojunction, however, becomes complicated in general, because both donor and acceptor may interface with each electrode when a donor/acceptor blend is formed by co-evaporation or spin-coating. Thus, a reversed stacking, for instance, an anode/acceptor/donor junction, would exist in a bulk-heterojunction OPV cell. This section addresses energy-level alignment in this uncommon heterostructure.

The heterojunction that we investigated consisted of a $\mathrm{MoO}_{3}$-covered $\mathrm{Au}(111) / \mathrm{C}_{60} 12 \mathrm{~nm} / \mathrm{ZnPc}$ structure. Analysis of UPS spectra clarified that the work function decreased upon depositing the $\mathrm{C}_{60}$ film onto the substrate (Figure 6a). The simulations showed that positive charges are present in the $\mathrm{C}_{60}$ layer near the interface with $\mathrm{MoO}_{3}$ through the emptying electrons from the $\mathrm{HOMO}$ of $\mathrm{C}_{60}$ by the high-work-function metal oxide (Figure $6 \mathrm{~b}$ ). The hole accumulation then leads to a downward shift of the vacuum level. Completion of the heterostructure by depositing $\mathrm{ZnPc}$ on top of the $\mathrm{C}_{60}$ film led to a huge vacuum-level shift. As seen in Figure 6a, work function decreases by $\sim 1.5 \mathrm{eV}$ upon completing the heterointerface. The simulations demonstrated that a large fraction of the energy shift was attributed to the change in potential in the $\mathrm{C}_{60}$ layer [23]. The rest of the decrease in work function originates from band-bending-like shifts in the ZnPc top layer. Note that the potential profile demonstrated is totally different from that for the standard stacking sequence, anode/ $\mathrm{ZnPc} / \mathrm{C}_{60}$ [21]. Therefore, symmetric energy-level alignment does not always hold, as has already been pointed out [19].
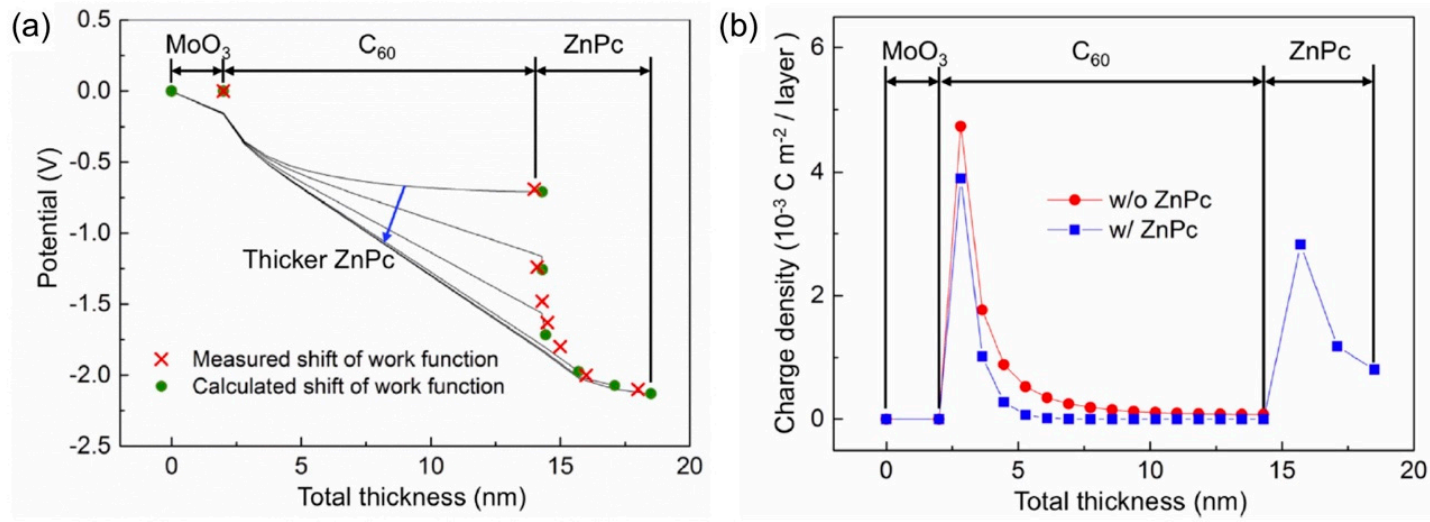

Figure 6. (a) Evolutions of measured (red crosses) and simulated (green circles) work functions. Black lines indicate electrostatic potential distributions within the respective layers. (b) Charge density distributions before (red) and after (blue) completion of the heterostructure. Reprinted with permission [23].

Analysis of the charge density profiles, shown in Figure $6 \mathrm{~b}$, helped form an understanding of the mechanism of energy-level alignment in this heterostructure. The work function of the $\mathrm{C}_{60}$ bottom layer was measured to be $6.0 \mathrm{eV}$, which is still high enough compared to the ionization energy of the top $\mathrm{ZnPc}$ layer. Thus, upon the deposition of $\mathrm{ZnPc}$ onto the $\mathrm{C}_{60}$ film, the electron of the $\mathrm{ZnPc} \mathrm{HOMO}$ gets emptied and then positive charges are generated in the $\mathrm{ZnPc}$ side at the interface (Figure $6 \mathrm{~b}$ ). It is worth mentioning that electrons in the $\mathrm{C}_{60}$ side at the heterointerface were absent in the simulation results. This indicates that interface dipoles are not formed in spite of the presence of positive charges on the $\mathrm{ZnPc}$ side. Since the charges in the $\mathrm{ZnPc}$ layer induce electrostatic fields across the $\mathrm{C}_{60} / \mathrm{ZnPc}$ heterojunction, a linear potential gradient appears in the $\mathrm{C}_{60}$ layer (black lines in Figure 6a). The lowering of the potential reduces the hole density near the $\mathrm{MoO}_{3}$ interface upon the formation of the heterointerface, as shown by the blue curve in Figure $6 \mathrm{~b}$. Since the potential gradient moves the $\mathrm{HOMO}$ away from $E_{\mathrm{F}}$, the pinning of the $\mathrm{C}_{60} \mathrm{HOMO}$ to $E_{\mathrm{F}}$ decreases. As a result, the concentration of holes in the $\mathrm{C}_{60}$ layer decreases after completing the heterostructure. 


\section{Conclusions}

In summary, contact-induced charges and resulting electrostatic fields govern the energetics at electrode/organic and organic heterointerfaces at thermodynamic equilibrium. Our studies on organic interfaces, related to conventional OPV cells, showed that substrate work-function and layer thicknesses are critical for determining the work function of organic films. Variation of the work function influences the magnitude of built-in potential at electrode/organic and organic heterointerfaces. Due to the Fermi-level pinning, a large fraction of dark charge accumulates at electrode interfaces, which may cause photocarrier recombination, as reported in Refs. $[45,46]$. It is however remarkable that contact-induced charges are present also at the donor/acceptor interface. The interface dark charges may assist exciton separation based on a simple electrostatic calculations [55], although experimental validation is necessary. We found that the top electrode and structural disorder considerably influence the charge distribution. The latter factor may be present also in bulk heterojunction, as a systematic study via cyclic voltammetry and UPS suggests the shortening of polymer conjugation length in an amorphous mixed phase with fullerene [49]. The DOS of the constituents in bulk heterojunction is not accessible by surface-sensitive UPS, because the polymer cap layer on the blend surface, segregated due to its low surface energy, can screen the buried molecular composition [56]. If the shape of DOS is modified in bulk heterojunction due to structural disordering (broadening and/or tailing), energy-level alignment near the electrode should be altered. This could be probed by measuring thickness-dependent work function with UPS or KP. We, however, point out that blending two dissimilar molecules alters ionization energy and electron affinity, due to the quadrupolar electrostatic field $[57,58]$. Taking this effect into account under assumption of identical molecular composition over a whole thickness range, fitting the thickness-dependent evolution of work function with electrostatic simulation will reveal information regarding static disorder in the bulk heterojunction for donor and acceptor. However, this analysis would be challenging.

Finally, let us add some comments on how to address state-of-the-art OPVs from the viewpoint of the energetic landscape. First, as mentioned just above, implementing the influence of molecular quadrupolar fields $[58,59]$ on changes in ionization energy and electron affinity at the donor/acceptor interface will give us a more precise energetic landscape at the interface. Second, based on the findings for conventional devices, the character of electronic structures of organic semiconductors already in use has to be considered. Efficient OPVs that have recently been reported on constitute donors with higher ionization energy than $\mathrm{ZnPc}$ and acceptors with a similar ionization energy or electron affinity to the donor [60-62]. These differences in electronic properties between conventional and recent donor/acceptor pairs must differentiate the energy-level lineup in OPVs. Electrostatic simulations for state-of-the-art donor/acceptor pairs are ongoing and will be reported elsewhere.

Funding: This research was funded by JSPS, grant number 15H06636 and 18K04944.

Acknowledgments: The author acknowledges financial support by the Alexander von Humboldt foundation. The author is grateful to Patrick Amsalem, Martin Oehzelt, Georg Heimel and Norbert Koch for fruitful collaboration and discussion.

Conflicts of Interest: The authors declare no conflict of interest.

\section{References}

1. Jinno, H.; Fukuda, K.; Xu, X.; Park, S.; Suzuki, Y.; Koizumi, M.; Yokota, T.; Osaka, I.; Takimiya, K.; Someya, T. Stretchable and waterproof elastomer-coated organic photovoltaics for washable electronic textile applications. Nat. Energy 2017, 2, 780-785. [CrossRef]

2. Tai, Q.; Yan, F. Emerging Semitransparent Solar Cells: Materials and Device Design. Adv. Mater. 2017, 29, 1700192. [CrossRef] [PubMed]

3. Brus, V.V.; Lee, J.; Luginbuhl, B.; Ko, S.; Bazan, G.C.; Nguyen, T. Solution-Processed Semitransparent Organic Photovoltaics: From Molecular Design to Device Performance. Adv. Mater. 2019, 1900904. [CrossRef] [PubMed] 
4. Cheng, P.; Li, G.; Zhan, X.; Yang, Y. Next-generation organic photovoltaics based on non-fullerene acceptors. Nat. Photonics 2018, 12,131-142. [CrossRef]

5. Meng, L.; Zhang, Y.; Wan, X.; Li, C.; Zhang, X.; Wang, Y.; Ke, X.; Xiao, Z.; Ding, L.; Xia, R.; et al. Organic and solution-processed tandem solar cells with 17.3\% efficiency. Science 2018, eaat2612. [CrossRef] [PubMed]

6. Liu, Q.; Jiang, Y.; Jin, K.; Qin, J.; Xu, J.; Li, W.; Xiong, J.; Liu, J.; Xiao, Z.; Sun, K.; et al. 18\% Efficiency organic solar cells. Sci. Bull. 2020, 65, 272-275. [CrossRef]

7. Lu, L.; Zheng, T.; Wu, Q.; Schneider, A.M.; Zhao, D.; Yu, L. Recent Advances in Bulk Heterojunction Polymer Solar Cells. Chem. Rev. 2015, 115, 12666-12731. [CrossRef]

8. Yan, C.; Barlow, S.; Wang, Z.; Yan, H.; Jen, A.K.-Y.; Marder, S.R.; Zhan, X. Non-fullerene acceptors for organic solar cells. Nat. Rev. Mater. 2018, 3, 1-19. [CrossRef]

9. Kim, D.Y.; Subbiah, J.; Sarasqueta, G.; So, F.; Ding, H.; Irfan; Gao, Y. The effect of molybdenum oxide interlayer on organic photovoltaic cells. Appl. Phys. Lett. 2009, 95, 093304. [CrossRef]

10. Irfan; Ding, H.; Gao, Y.; Kim, D.Y.; Subbiah, J.; So, F. Energy level evolution of molybdenum trioxide interlayer between indium tin oxide and organic semiconductor. Appl. Phys. Lett. 2010, 96, 073304. [CrossRef]

11. Akaike, K.; Kanai, K.; Ouchi, Y.; Seki, K. Impact of Ground-State Charge Transfer and Polarization Energy Change on Energy Band Offsets at Donor/Acceptor Interface in Organic Photovoltaics. Adv. Funct. Mater. 2010, 20, 715-721. [CrossRef]

12. Osikowicz, W.; de Jong, M.P.; Salaneck, W.R. Formation of the Interfacial Dipole at Organic-Organic Interfaces: $\mathrm{C}_{60}$ /Polymer Interfaces. Adv. Mater. 2007, 19, 4213-4217. [CrossRef]

13. Wilke, A.; Mizokuro, T.; Blum, R.-P.; Rabe, J.P.; Koch, N. Electronic Properties of Cu-Phthalocyanine/Fullerene Planar and Bulk Hetereojunctions on PEDOT:PSS. IEEE J. Sel. Top. Quantum Electron. 2010, 16, 1732-1737. [CrossRef]

14. Wilke, A.; Endres, J.; Hörmann, U.; Niederhausen, J.; Schlesinger, R.; Frisch, J.; Amsalem, P.; Wagner, J.; Gruber, M.; Opitz, A.; et al. Correlation between interface energetics and open circuit voltage in organic photovoltaic cells. Appl. Phys. Lett. 2012, 101, 233301. [CrossRef]

15. Tang, J.X.; Lee, C.S.; Lee, S.T. Electronic structures of organic/organic heterojunctions: From vacuum level alignment to Fermi level pinning. J. Appl. Phys. 2007, 101, 064504. [CrossRef]

16. Nakayama, Y.; Nguyen, T.L.; Ozawa, Y.; Machida, S.; Sato, T.; Tokairin, H.; Noguchi, Y.; Ishii, H. Complete Demonstration of the Valence Electronic Structure Inside a Practical Organic Solar Cell Probed by Low Energy Photoemission. Adv. Energy Mater. 2014, 4, 1301354. [CrossRef]

17. Frisch, J.; Schubert, M.; Preis, E.; Rabe, J.P.; Neher, D.; Scherf, U.; Koch, N. Full electronic structure across a polymer heterojunction solar cell. J. Mater. Chem. 2012, 22, 4418. [CrossRef]

18. Ishii, H.; Sugiyama, K.; Ito, E.; Seki, K. Energy Level Alignment and Interfacial Electronic Structures at Organic/Metal and Organic/Organic Interfaces. Adv. Mater. 1999, 11, 605-625. [CrossRef]

19. Braun, S.; de Jong, M.P.; Osikowicz, W.; Salaneck, W.R. Influence of the electrode work function on the energy level alignment at organic-organic interfaces. Appl. Phys. Lett. 2007, 91, 202108. [CrossRef]

20. Zhao, W.; Salomon, E.; Zhang, Q.; Barlow, S.; Marder, S.R.; Kahn, A. Substrate-dependent electronic structure of an organic heterojunction. Phys. Rev. 2008, 77. [CrossRef]

21. Akaike, K.; Koch, N.; Heimel, G.; Oehzelt, M. The Impact of Disorder on the Energy Level Alignment at Molecular Donor-Acceptor Interfaces. Adv. Mater. Interfaces 2015, 2, 1500232. [CrossRef]

22. Oehzelt, M.; Koch, N.; Heimel, G. Organic semiconductor density of states controls the energy level alignment at electrode interfaces. Nat. Commun. 2014, 5. [CrossRef] [PubMed]

23. Akaike, K.; Koch, N.; Oehzelt, M. Fermi level pinning induced electrostatic fields and band bending at organic heterojunctions. Appl. Phys. Lett. 2014, 105, 223303. [CrossRef]

24. Oehzelt, M.; Akaike, K.; Koch, N.; Heimel, G. Energy-level alignment at organic heterointerfaces. Sci. Adv. 2015, 1, e1501127. [CrossRef] [PubMed]

25. Peisert, H.; Knupfer, M.; Schwieger, T.; Auerhammer, J.M.; Golden, M.S.; Fink, J. Full characterization of the interface between the organic semiconductor copper phthalocyanine and gold. J. Appl. Phys. 2002, 91, 4872. [CrossRef]

26. Kröger, I.; Stadtmüller, B.; Stadler, C.; Ziroff, J.; Kochler, M.; Andreas, S.; Pollinger, F.; Lee, T.-L.; Zegenhagen, J.; Reinert, F.; et al. Submonolayer growth of copper-phthalocyanine on $\mathrm{Ag}(111)$. New J. Phys. 2010, 12, 083038. [CrossRef] 
27. Tanaka, Y.; Takahashi, K.; Kuzumaki, T.; Yamamoto, Y.; Hotta, K.; Harasawa, A.; Miyoshi, Y.; Yoshikawa, H.; Ouchi, Y.; Ueno, N.; et al. Intermolecular band dispersion in a self-assembled phthalocyanine derivative film: The case of tetrakis(thiadiazole)porhyrazine. Phys. Rev. 2010, 82. [CrossRef]

28. Hayashi, N.; Ishii, H.; Ouchi, Y.; Seki, K. Examination of band bending at buckminsterfullerene $\left(\mathrm{C}_{60}\right) / \mathrm{metal}$ interfaces by the Kelvin probe method. J. Appl. Phys. 2002, 92, 3784-3793. [CrossRef]

29. Perdigón-Toro, L.; Zhang, H.; Markina, A.; Yuan, J.; Hosseini, S.M.; Wolff, C.M.; Zuo, G.; Stolterfoht, M.; Zou, Y.; Gao, F.; et al. Barrierless Free Charge Generation in the High-Performance PM6:Y6 Bulk Heterojunction Non-Fullerene Solar Cell. Adv. Mater. 2020, 32, 1906763. [CrossRef]

30. Akaike, K. Advanced understanding on electronic structure of molecular semiconductors and their interfaces. Jpn. J. Appl. Phys. 2018, 57, 03EA03. [CrossRef]

31. Heilmeier, G.H.; Warfield, G. Investigation of Bulk Currents in Metal-Free Phthalocyanine Crystals. J. Chem. Phys. 1963, 38, 163-168. [CrossRef]

32. Wang, H.; Amsalem, P.; Heimel, G.; Salzmann, I.; Koch, N.; Oehzelt, M. Band-Bending in Organic Semiconductors: The Role of Alkali-Halide Interlayers. Adv. Mater. 2014, 26, 925-930. [CrossRef] [PubMed]

33. Amsalem, P.; Niederhausen, J.; Wilke, A.; Heimel, G.; Schlesinger, R.; Winkler, S.; Vollmer, A.; Rabe, J.P.; Koch, N. Role of charge transfer, dipole-dipole interactions, and electrostatics in Fermi-level pinning at a molecular heterojunction on a metal surface. Phys. Rev. 2013, 87. [CrossRef]

34. Niederhausen, J.; Amsalem, P.; Wilke, A.; Schlesinger, R.; Winkler, S.; Vollmer, A.; Rabe, J.P.; Koch, N. Doping of $\mathrm{C}_{60}$ (sub)monolayers by Fermi-level pinning induced electron transfer. Phys. Rev. 2012, 86. [CrossRef]

35. Winkler, S.; Amsalem, P.; Frisch, J.; Oehzelt, M.; Heimel, G.; Koch, N. Probing the energy levels in hole-doped molecular semiconductors. Mater. Horiz. 2015, 2, 427-433. [CrossRef]

36. Shallcross, R.C.; Stubhan, T.; Ratcliff, E.L.; Kahn, A.; Brabec, C.J.; Armstrong, N.R. Quantifying the Extent of Contact Doping at the Interface between High Work Function Electrical Contacts and Poly(3-hexylthiophene) (P3HT). J. Phys. Chem. Lett. 2015, 6, 1303-1309. [CrossRef]

37. Rand, B.P.; Cheyns, D.; Vasseur, K.; Giebink, N.C.; Mothy, S.; Yi, Y.; Coropceanu, V.; Beljonne, D.; Cornil, J.; Brédas, J.-L.; et al. The Impact of Molecular Orientation on the Photovoltaic Properties of a Phthalocyanine/Fullerene Heterojunction. Adv. Funct. Mater. 2012, 22, 2987-2995. [CrossRef]

38. Chen, W.; Qi, D.-C.; Huang, H.; Gao, X.; Wee, A.T.S. Organic-Organic Heterojunction Interfaces: Effect of Molecular Orientation. Adv. Funct. Mater. 2011, 21, 410-424. [CrossRef]

39. Ngongang Ndjawa, G.O.; Graham, K.R.; Li, R.; Conron, S.M.; Erwin, P.; Chou, K.W.; Burkhard, G.F.; Zhao, K.; Hoke, E.T.; Thompson, M.E.; et al. Impact of Molecular Orientation and Spontaneous Interfacial Mixing on the Performance of Organic Solar Cells. Chem. Mater. 2015, 27, 5597-5604. [CrossRef]

40. Opitz, A.; Wilke, A.; Amsalem, P.; Oehzelt, M.; Blum, R.-P.; Rabe, J.P.; Mizokuro, T.; Hörmann, U.; Hansson, R.; Moons, E.; et al. Organic heterojunctions: Contact-induced molecular reorientation, interface states, and charge re-distribution. Sci. Rep. 2016, 6, 21291. [CrossRef]

41. Tengstedt, C.; Osikowicz, W.; Salaneck, W.R.; Parker, I.D.; Hsu, C.-H.; Fahlman, M. Fermi-level pinning at conjugated polymer interfaces. Appl. Phys. Lett. 2006, 88, 053502. [CrossRef]

42. Yang, J.-P.; Bussolotti, F.; Kera, S.; Ueno, N. Origin and role of gap states in organic semiconductor: As the nature of organic molecular crystals. J. Phys. Appl. Phys. 2017. [CrossRef]

43. Yoshida, H. Low-Energy Inverse Photoemission Study on the Electron Affinities of Fullerene Derivatives for Organic Photovoltaic Cells. J. Phys. Chem. 2014, 118, 24377-24382. [CrossRef]

44. Akaike, K.; Kubozono, Y. Correlation between energy level alignment and device performance in planar heterojunction organic photovoltaics. Org. Electron. 2013, 14, 1-7. [CrossRef]

45. Würfel, U.; Perdigón-Toro, L.; Kurpiers, J.; Wolff, C.M.; Caprioglio, P.; Rech, J.J.; Zhu, J.; Zhan, X.; You, W.; Shoaee, S.; et al. Recombination between Photogenerated and Electrode-Induced Charges Dominates the Fill Factor Losses in Optimized Organic Solar Cells. J. Phys. Chem. Lett. 2019, 10, 3473-3480. [CrossRef]

46. Wang, J.; Xu, L.; Lee, Y.-J.; De Anda Villa, M.; Malko, A.V.; Hsu, J.W.P. Effects of Contact-Induced Doping on the Behaviors of Organic Photovoltaic Devices. Nano Lett. 2015, 15, 7627-7632. [CrossRef]

47. Izawa, S.; Shintaku, N.; Hiramoto, M. Effect of Band Bending and Energy Level Alignment at the Donor/Acceptor Interface on Open-Circuit Voltage in Organic Solar Cells. J. Phys. Chem. Lett. 2018, 9, 2914-2918. [CrossRef]

48. Breuer, T.; Karthäuser, A.; Witte, G. Effects of Molecular Orientation in Acceptor-Donor Interfaces between Pentacene and $\mathrm{C}_{60}$ and Diels-Alder Adduct Formation at the Molecular Interface. Adv. Mater. Interfaces 2016, 3, 1500452. [CrossRef] 
49. Sweetnam, S.; Graham, K.R.; Ngongang Ndjawa, G.O.; Heumüller, T.; Bartelt, J.A.; Burke, T.M.; Li, W.; You, W.; Amassian, A.; McGehee, M.D. Characterization of the Polymer Energy Landscape in Polymer: Fullerene Bulk Heterojunctions with Pure and Mixed Phases. J. Am. Chem. Soc. 2014, 136, 14078-14088. [CrossRef]

50. Sai, N.; Gearba, R.; Dolocan, A.; Tritsch, J.R.; Chan, W.-L.; Chelikowsky, J.R.; Leung, K.; Zhu, X. Understanding the Interface Dipole of Copper Phthalocyanine $(\mathrm{CuPc}) / \mathrm{C}_{60}$ : Theory and Experiment. J. Phys. Chem. Lett. 2012, 3, 2173-2177. [CrossRef]

51. Lin, X.; Purdum, G.E.; Zhang, Y.; Barlow, S.; Marder, S.R.; Loo, Y.-L.; Kahn, A. Impact of a Low Concentration of Dopants on the Distribution of Gap States in a Molecular Semiconductor. Chem. Mater. 2016, 28, 2677-2684. [CrossRef]

52. Stadtmüller, B.; Gruenewald, M.; Peuker, J.; Forker, R.; Fritz, T.; Kumpf, C. Molecular Exchange in a Heteromolecular PTCDA/CuPc Bilayer Film on Ag(111). J. Phys. Chem. 2014, 118, 28592-28602. [CrossRef]

53. Wang, Q.; Franco-Cañellas, A.; Ji, P.; Bürker, C.; Wang, R.-B.; Broch, K.; Thakur, P.K.; Lee, T.-L.; Zhang, H.; Gerlach, A.; et al. Bilayer Formation vs Molecular Exchange in Organic Heterostructures: Strong Impact of Subtle Changes in Molecular Structure. J. Phys. Chem. 2018, 122, 9480-9490. [CrossRef]

54. Akaike, K.; Onishi, A.; Wakayama, Y.; Kanai, K. Structural Disordering upon Formation of Molecular Heterointerfaces. J. Phys. Chem. 2019, 123, 12242-12248. [CrossRef]

55. Arkhipov, V.I.; Heremans, P.; Bässler, H. Why is exciton dissociation so efficient at the interface between a conjugated polymer and an electron acceptor? Appl. Phys. Lett. 2003, 82, 4605-4607. [CrossRef]

56. Guan, Z.-L.; Kim, J.B.; Wang, H.; Jaye, C.; Fischer, D.A.; Loo, Y.-L.; Kahn, A. Direct determination of the electronic structure of the poly(3-hexylthiophene):phenyl-[6,6]-C61 butyric acid methyl ester blend. Org. Electron. 2010, 11, 1779-1785. [CrossRef]

57. Poelking, C.; Andrienko, D. Design Rules for Organic Donor-Acceptor Heterojunctions: Pathway for Charge Splitting and Detrapping. J. Am. Chem. Soc. 2015, 137, 6320-6326. [CrossRef]

58. Schwarze, M.; Tress, W.; Beyer, B.; Gao, F.; Scholz, R.; Poelking, C.; Ortstein, K.; Gunther, A.A.; Kasemann, D.; Andrienko, D.; et al. Band structure engineering in organic semiconductors. Science 2016, 352, 1446-1449. [CrossRef]

59. Poelking, C.; Tietze, M.; Elschner, C.; Olthof, S.; Hertel, D.; Baumeier, B.; Würthner, F.; Meerholz, K.; Leo, K.; Andrienko, D. Impact of mesoscale order on open-circuit voltage in organic solar cells. Nat. Mater. 2014, 14, 434-439. [CrossRef]

60. Liu, J.; Chen, S.; Qian, D.; Gautam, B.; Yang, G.; Zhao, J.; Bergqvist, J.; Zhang, F.; Ma, W.; Ade, H.; et al. Fast charge separation in a non-fullerene organic solar cell with a small driving force. Nat. Energy 2016, 1, 16089. [CrossRef]

61. Chen, S.; Wang, Y.; Zhang, L.; Zhao, J.; Chen, Y.; Zhu, D.; Yao, H.; Zhang, G.; Ma, W.; Friend, R.H.; et al. Efficient Nonfullerene Organic Solar Cells with Small Driving Forces for Both Hole and Electron Transfer. Adv. Mater. 2018, 30, 1804215. [CrossRef] [PubMed]

62. Yuan, J.; Zhang, Y.; Zhou, L.; Zhang, G.; Yip, H.-L.; Lau, T.-K.; Lu, X.; Zhu, C.; Peng, H.; Johnson, P.A.; et al. Single-Junction Organic Solar Cell with over 15\% Efficiency Using Fused-Ring Acceptor with Electron-Deficient Core. Joule 2019, 3, 1140-1151. [CrossRef]

(C) 2020 by the author. Licensee MDPI, Basel, Switzerland. This article is an open access article distributed under the terms and conditions of the Creative Commons Attribution (CC BY) license (http://creativecommons.org/licenses/by/4.0/). 